\title{
The Asia Climate Policy Hub: Prioritizing Climate Smart Livestock Interventions for Indonesia
}

\author{
Godefroy Grosjean, Douxchamps S, Traore SA \\ International Center for Tropical Agriculture (CIAT), \\ Regional Office for Asia, Hanoi, Vietnam \\ g.grosjean@cgiar.org
}

\begin{abstract}
Both climate change and population increase are putting pressure on natural resources, and livestock production must therefore become more and more efficient. CIAT has developed an action plan in five steps to ensure sustainable and profitable livestock production in Indonesia. First, climate smart livestock profiling provides an initial prioritization of climate smart technologies and identifies barriers to adoption and reviews the policy and institutional environment. A landscape approach is then used to characterize risk and vulnerability of livestock systems, and map promising techniques to particular landscape units. Third, climate smart villages piloting are established for contrasting agroecological zones, and participatory action research is used to test innovative and resource efficient production systems, both on a biophysical and economic point of view. This is followed by a cost-benefit analysis to assess economic costs and benefits for business-as-usual approaches compared to scenarios where climate-smart practices are adopted. Finally in the fifth step, CIAT develops with its country partners a climate smart investment plan, where potential impacts of the new practices on food security, water use and greenhouse gas emissions are modelled until 2050. The five steps action plan would allow Indonesia to increase profitability and efficiency of its livestock sector.
\end{abstract}

Key Words: Climate Smart Livestock, Climate Smart Technologies, Climate Smart Investment Plan

\section{CLIMATE CHANGE CHALLENGES FOR THE AGRICULTURE SECTOR}

The agricultural sector is highly exposed to the challenges induced by climate change. Furthermore, both climate change and population increase are putting pressure on natural resources, therefore livestock production which has a significant share in agriculture must become more and more efficient.

Effectively addressing these challenges requires a paradigm shift in national and international agricultural policies. Worldwide, governments are facing the complex task to meet the commitments of the Paris Agreement, i.e. limiting global warming to below $2{ }^{\circ} \mathrm{C}$ by drastically reducing global emissions by 2050, while at the same time adjusting to a growing population and a changing diet. The active involvement of multiple players such as donors, policymakers as well as the private sector is crucial to achieve this goal. All these stakeholders need relevant, accessible, science-based and interdisciplinary advice to facilitate decision-making processes and implement new policies or strategies. 


\section{THE CLIMATE POLICY HUB}

The Climate Policy Hub (CPH) is a competence center for socio-economic analyses supporting agricultural policies. By providing targeted, science-based and timely advice to key players from the public and private sectors, the CPH supports decision-makers in designing and implementing effective climate policies and strategies for the agricultural sector. Essentially the $\mathrm{CPH}$ strives to provide the right information to the right people at the right time in an effective format.

Backed by CIAT's 50 years of research experience on tropical agriculture, the $\mathrm{CPH}$ is a unique opportunity of creating an interface between CIAT scientific output on climate change and decision-making processes in agriculture. As a center for economic policy analysis, the $\mathrm{CPH}$ strategically combines a wide array of methodologies and scientific tools for comprehensive economic and policy analysis. Its integrative approach allows to tailor knowledge and develop decision-support tools that build capacities at multiple levels for effective climate policy. To support prioritization of climate smart agriculture (CSA) interventions for the livestock sector in Indonesia, CIAT is suggesting a multi-steps approach to support the development of a comprehensive CSA strategy.

\section{THE CLIMATE POLICY HUB STRATEGY}

The CPH operates on four stages: (1) Undertake a stock taking of climate policies, actions and associated challenges; (2) Prioritize interventions by evaluating the effectiveness of policy designs in emissions reduction and other impacts; (3) Develop a systematic framework to analyze quantitatively and qualitatively trade-offs across policy designs; and (4) Inform policy design, also providing support for implementation and monitoring.

\section{The CANT Asia Climate Policy I lub: Tools to support different stages of decision making}

\section{$\mathrm{OCPH}$}

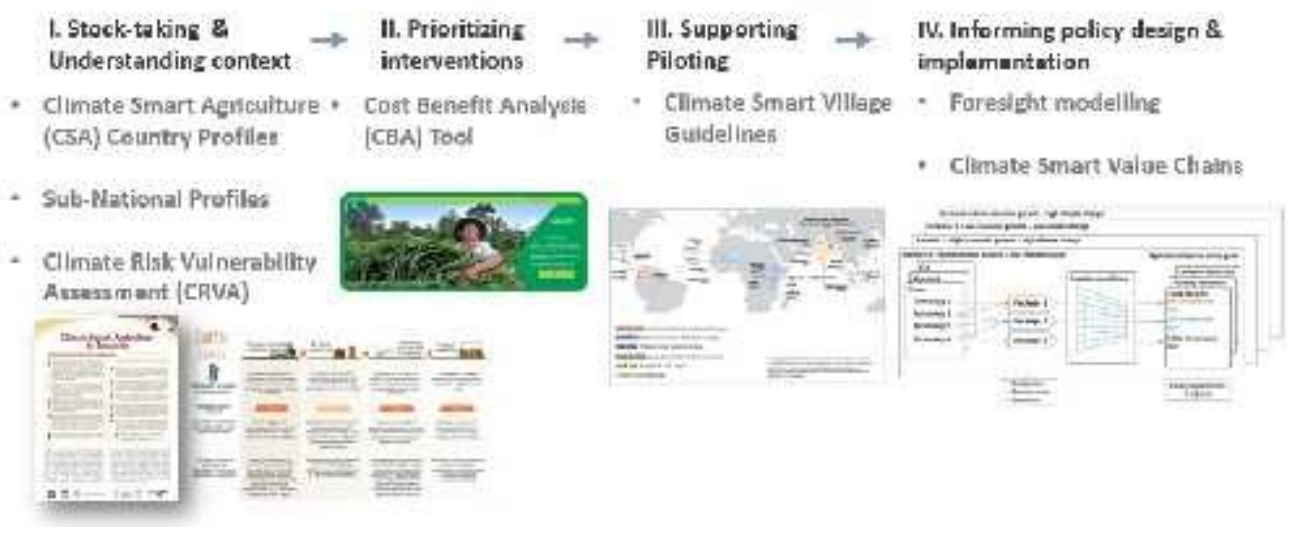

\section{STOCK-TAKING AND PRIORITIZATION OF INTERVENTIONS}

Ensuring availability and access to relevant information is a first step in creating an enabling environment for a resilient, low-carbon and high-productive agriculture sector development. Advancing this vision on the public agenda requires policies and institutions that are supportive of an integrated vision to agricultural development. It also 
requires sufficient and adequate institutional capacity (human, technical, and financial) to prioritize actions and to enable mechanisms for minimizing barriers and constraints to adoption, especially among farmers. Even in the absence of readily available, relevant information, decision-makers are faced with the difficulty to identify and prioritize bestbet investment and policy actions that maximize benefits to society.

Several tools exist for the stock-taking and prioritization stages of CSA interventions. One tool the $\mathrm{CPH}$ uses to facilitate this process are the CSA country profiles. These are brief documents that aim to provide context for agricultural investment planning and program development. They take stock of ongoing CSA activities at national level and offer cutting edge information on enabling environments and barriers for mainstreaming CSA. Essentially, the CSA Country Profiles provide an overview of the current agricultural context, institutional and policy frameworks in a selected country. They also bring forth cutting-edge approaches and methods for understanding and assessing potential impacts of CSA actions, by highlighting critical dimensions that cut across the three CSA pillars, productivity, adaptation, and mitigation. Avenues for CSA financing are reviewed, to pinpoint existing resources, gaps, and potential additional funding options for CSA interventions.

By 2018, CIAT, together with local and international partner organizations, has developed more than 30 CSA Country Profiles globally, of which seven have been published in Asia, with several more under development. Next to national level profiles, the $\mathrm{CPH}$ also develops sub-national Climate Risk Profiles (CRPs), targeting climate risks across agricultural value chains at province or district level. Currently, more than 50 CRPs have or are being developed by CIAT in Kenya, Mexico, Pakistan and the Philippines. CRPs offer an additional value-chain specific analysis of CSA entry-points, catering to the need of developing context-specific strategies for CSA interventions. CRPs identify key local value chain commodities and outline the most problematic climatic hazards and vulnerabilities, and highlight risks posed by these hazards across the value chain. The profiles then make tailored recommendations of adaptation strategies and services available for combating the risks associated with these hazards.

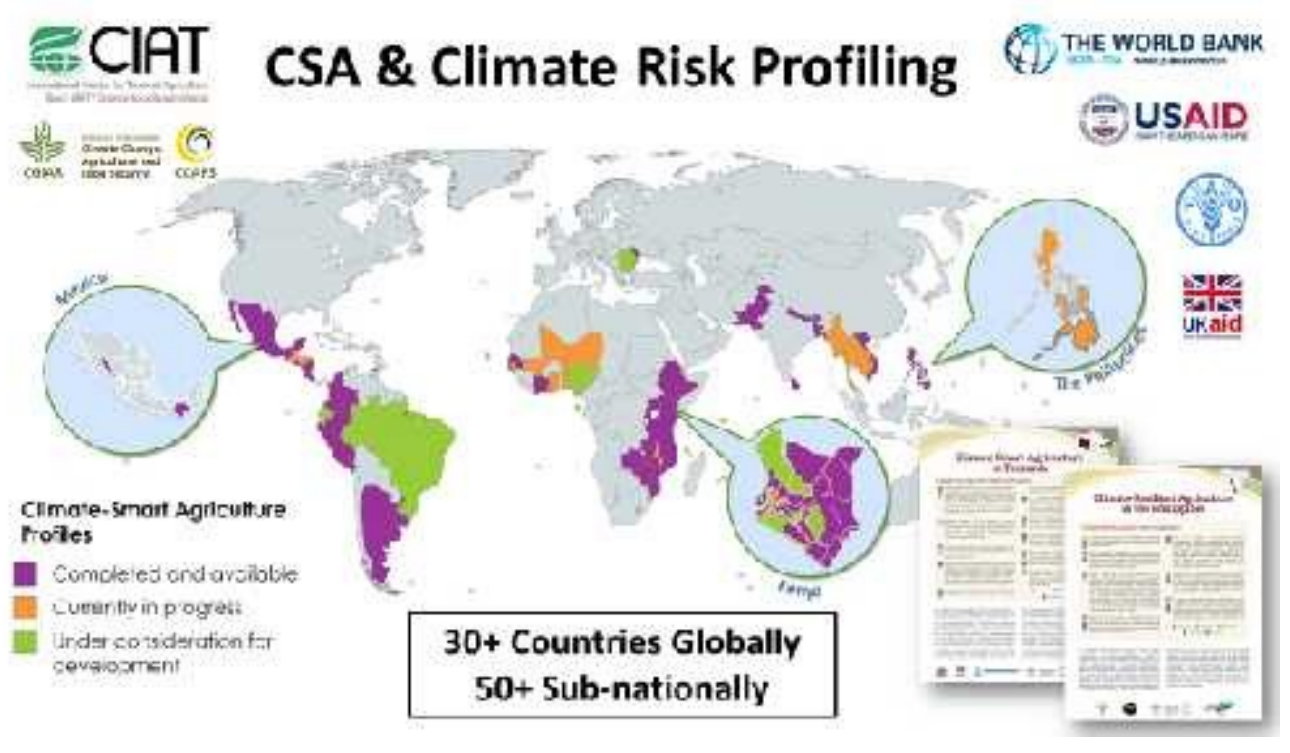


Once different CSA interventions have been prioritized, CIAT's cost-benefit analysis (CBA) tool allows a more in-depth analysis of economic profitability of these interventions at farm level. This tool is most extensive in its analysis, allowing to directly compare all costs and benefits of a CSA investment over its lifetime, including externalities resulting from CSA adoption (such as increased soil fertility).

\section{PILOTING AND SCALING: INFORM POLICY DESIGN, IMPLEMENTATION AND MONITORING}

In the piloting and scaling phase, outcomes of prioritization support tools are implemented on the ground (e.g. in supporting design of Climate Smart Villages; see also Aggarwal et al. 2018), or by using economic foresight modeling to support upscaling results towards developing national-level policy and investment strategies, such as in the World Bank Climate Smart Investment Plan for Bangladesh (CSAIP).

Climate Smart Villages piloting mixed systems address the need for proven and effective CSA options, the Climate-Smart Village (CSV) approach is a mean to agricultural research for development (AR4D) in the context of climate change. A matchmaking study will be undertaken to identify the most adapted mixed crop-livestock-tree systems for contrasting agro-ecological zones and in different contexts of Indonesia. Using the information from in the CSA, a CSV integrating resilient systems were natural resources are used as efficiently as possible will be designed. Improved forages (both grasses and legumes) will be integrated in innovative systems, considering both spatial and temporal entry points. The newly designed systems will take into account both biophysical and socio-economic variables, trying to maximize farm productivity and natural resources use, while minimizing negative environmental impact. The CSV approach is founded on the principles of participatory action research for grounding research on appropriate and location/context-specific enabling conditions, generating greater evidence of CSA effectiveness in a real-life setting and facilitating codevelopment of scaling mechanisms towards landscapes, subnational and national levels.

Building the CSAIP strategic foresight component, the $\mathrm{CPH}$ and IIASA have developed the agricultural sector model of Bangladesh to analyze future production possibilities and trade-offs of key crop, livestock and fishery commodities. The model outcomes are assessed under alternative investment and land use options as well as across different climate change and economic growth scenarios. The model thus allows to prioritize current and likely future bottlenecks for production and resource use under business-as-usual strategies; and to explore how different land use scenarios and investments in climate smart agriculture technologies can best help achieve national government targets related to food security, climate policy/NDCs and sustainable use of natural resources. The results are therefore highly relevant for identifying and prioritizing policy actions, investments and knowledge gaps to inform agriculture sector planning for a productive, resilient and low-emissions agricultural sector development in Bangladesh.

\section{CONCLUSION}

Climate Smart Agriculture is highly context specific, no one size fits all solution. It is crucial to have a structured process for CSA planning. A proper planning requires to understand the context and challenges of the agriculture sector at various scales, evaluate financial implications for farmers and economic return for society. Pilot might be necessary, especially for new CSA technologies and practices. It is important to keep in 
mind the bigger picture and how CSA interventions are related to long-term policy objectives. Once the required activities are identified, innovative financial services and support need to be put into place as well as targeted incentives such as fiscal reform and climate smart subsidies.

\section{REFERENCES}

Aggarwal PK, Jarvis A, Campbell BM, Zougmoré RB, Khatri-Chhetri A, Vermeulen SJ, Loboguerrero A, Sebastian LS, Kinyangi J, Bonilla-Findji O, Radeny M, Recha J, Martinez-Baron D, Ramirez-Villegas J, Huyer S, Thornton P, Wollenberg E, Hansen J, Alvarez-Toro P, Aguilar-Ariza A, Arango-Londoño D, Patiño-Bravo V, Rivera O, Ouedraogo M, Tan Yen B. 2018. The climate-smart village approach: framework of an integrative strategy for scaling up adaptation options in agriculture. Ecol Soc. 23:14. https://doi.org/10.5751/ES-09844-230114

CGIAR Research Program on Climate Change, Agriculture and Food Security (CCAFS). The CSA Country Profiles. https://ccafs.cgiar.org/publications/csa-country-profiles

FAO. 2016. The state of food and agriculture: Climate change, agriculture and food security. www.fao.org/3/a-i6030e.pdf

FAO. 2017a. FAO strategy on climate change. www.fao.org/3/a-i7175e.pdf

FAO. 2017b. FAO Strategy on climate change - action plan results framework. www.fao.org/fileadmin/user_upload/bodies/Progr_Comm/PC_122documents/MU632e.pdf

FAO. 2018. FAO Regional initiatives: Supporting member countries to achieve the sustainable development goals. www.fao.org/3/i8498en/I8498EN.pdf

International Center for Tropical Agriculture (CIAT). The Climate Policy Hub. https://ciat.cgiar.org/what-we-do/climate-smart-agriculture/asia-climate-policy-hub/

International Center for Tropical Agriculture (CIAT). The Cost Benefit Analysis Tool. http://cbatool.ciat.cgiar.org/ 